\title{
Enhanced osteogenesis on titanium implants by UVB photofunctionalization of hydrothermally grown $\mathrm{TiO}_{2}$ coatings
}

Journal of Biomaterials Applications 20I5, Vol. 30(I) 7I-84

(C) The Author(s) 2015

Reprints and permissions:

sagepub.co.uk/journalsPermissions.nav

DOI: |0.| I77/08853282।556909|

ba.sagepub.com

@SAGE

\author{
Martina Lorenzetti' ${ }^{1,2}$, Olga Dakischew ${ }^{3}$, Katja Trinkaus ${ }^{3}$, \\ Katrin Susanne Lips ${ }^{3}$, Reinhard Schnettler ${ }^{3,4}$, \\ Spomenka Kobe ${ }^{1,2}$ and Saša Novak ${ }^{1,2}$
}

\begin{abstract}
Even though Ti-based implants are the most used materials for hard tissue replacement, they may present lack of osseointegration on the long term, due to their inertness. Hydrothermal treatment (HT) is a useful technique for the synthesis of firmly attached, highly crystalline coatings made of anatase titanium dioxide $\left(\mathrm{TiO}_{2}\right)$, providing favorable nanoroughness and higher exposed surface area, as well as greater hydrophilicity, compared to the native amorphous oxide on pristine titanium. The hydrophilicity drops even more by photofunctionalization of the nanostructured $\mathrm{TiO}_{2}$-anatase coatings under UV light. Human mesenchymal stem cells exhibited a good response to the combination of the positive surface characteristics, especially in respect to the UVB pre-irradiation. The results showed that the cells were not harmed in terms of viability; even more, they were encouraged to differentiate in osteoblasts and to become osteogenically active, as confirmed by the calcium ion uptake and the formation of well-mineralized, bone-like nodule structures. In addition, the enrichment of hydroxyl groups on the HT-surfaces by UVB photofunctionalization accelerated the cell differentiation process and greatly improved the osteogenesis in comparison with the nonirradiated samples. The optimal surface characteristics of the HT-anatase coatings as well as the high potentiality of the photo-induced hydrophilicity, which was reached during a relatively short pre-irradiation time $(5 \mathrm{~h})$ with UVB light, can be correlated with better osseointegration ability in vivo; among the samples, the superior biological behavior of the roughest and most hydrophilic HT coating makes it a good candidate for further studies and applications.
\end{abstract}

\section{Keywords}

$\mathrm{TiO}_{2}$, photofunctionalization, osteogenesis, hMSCs, biocompatibility, hydrothermal treatment, bone

\section{Introduction}

Osteogenesis is a specific aspect of the bone formation, occurring at the implant surface; it denotes the stimulation of the osteoprogenitor cell proliferation and the osteoblast biosynthetic activity ${ }^{1}$ to improve the production of osteoid matrix, which then mineralizes and leads to the new bone formation. This process is considered extremely important for the life expectation and osseointegration of the metallic implant. Indeed, the mere presence of an implant can critically influence the tissue healing process; for instance, the biocompatibility of a biomaterial depends on its surface properties, such as chemistry and chemical functionalities, topography and roughness, wettability, surface charge, elasticity/stiffness, etc. ${ }^{2,3}$ Consequently, implants with different surface properties are expected to affect differently the tissue integration.

Titanium and its alloys, the most used materials for hard tissue replacement, are classified as bioinert, due to the passivation layer of amorphous titanium dioxide

'Department of Nanostructured Materials, Jožef Stefan Institute, Ljubljana, Slovenia

2Jožef Stefan International Postgraduate School, Ljubljana, Slovenia

${ }^{3}$ Laboratory for Experimental Trauma Surgery, Justus-Liebig-University Giessen, Giessen, Germany

${ }^{4}$ Department of Trauma Surgery, University Hospital of Giessen and Marburg, Giessen, Germany

Corresponding author:

Martina Lorenzetti, Department of Nanostructured Materials, Jožef Stefan Institute, Jamova cesta 39, 1000 Ljubljana, Slovenia.

Email: martina.lorenzetti@ijs.si 
$\left(\mathrm{TiO}_{2}\right)$, which is naturally formed on the surface. ${ }^{4,5}$ Lots of efforts have been put in modifying the metal surface by the development of coatings, to render it more bioactive and to improve the osseointegration. Among the available techniques, hydrothermal treatment (HT) revealed to be an interesting method for the growth of firmly attached, highly crystalline coatings made of titanium dioxide. ${ }^{6} \mathrm{TiO}_{2}$-films have been shown to stimulate osteoblast and mesenchymal cell line attachment and growth. ${ }^{7,8}$ In addition, Zhao et al. ${ }^{9}$ demonstrated that the $\mathrm{TiO}_{2}$ in the form of anatase crystalline phase was more favorable for hepatocyte proliferation than the rutile phase, meaning that the $\mathrm{TiO}_{2}$ crystallinity played a role in biocompatibility too.

Moreover, as semiconductor, nanosized anatase can undergo photo-induced wettability when irradiated with ultraviolet (UV) light, resulting in a super-hydrophilic state of the surface, due to the uptake of hydroxyl $\mathrm{OH}^{-}$groups on the outermost layer. ${ }^{10,11}$ It was reported that this peculiar surface physico-chemical state enhanced the biocompatibility and bioactivity of the surface. ${ }^{12,13}$ Very recently, a new phenomenon, called "photofunctionalization", has been revealed to occur after prolonged exposure to UVC irradiation $(48 \mathrm{~h})$, which promoted remarkably high cell attachment, proliferation and differentiation on titanium. ${ }^{14,15}$ Gao et al. ${ }^{16}$ claimed that the critical aspect depends on the UV wavelength: starting from micro-arc oxidized titanium, the UVC-treated surfaces exhibited superior bioactivity than the UVA-treated ones. The authors declared that the photo-induced hydrophilicity of the $\mathrm{TiO}_{2}$-surfaces was achieved using UVA irradiation, while only the UVC irradiation was able to provoke a photolytic effect (direct decomposition of hydrocarbons), obtaining highly cleaned surfaces. However, the prominent role of either the surface photo-induced hydrophilicity or the photolysis by UVC, in respect to the bioactivity, is still controversial in literature. In our previous works ${ }^{17,18}$ it was shown that hydrothermally grown $\mathrm{TiO}_{2}$-coatings provided advantageous surface characteristics, without affecting the bulk mechanical properties of the substrates; specifically, the HT coatings were made of firmly attached anatase nanocrystals, which provided higher corrosion-resistance, surface nanoroughness and a more hydrophilic nature than the bare titanium. All these features are expected to positively influence the biological response towards the coated titanium. We also proved that the photoactivation of $\mathrm{HT} \mathrm{TiO}_{2}$-anatase coatings under UVAUVB irradiation was retained up to 2 weeks, with a slow recovery when storing the samples in dark. ${ }^{18}$

Starting from these achievements, we decided to use for the first time only UVB light $(302 \mathrm{~nm})$ and to reduce the pre-irradiation time down to $5 \mathrm{~h}$ for applicability reasons. Therefore, the aim of this study was to verify the effect of the UVB pre-irradiation of hydrothermally grown $\mathrm{TiO}_{2}$-anatase coatings on human primary cell viability, differentiation and osteogenesis.

\section{Materials and methods}

\section{Hydrothermal synthesis of $\mathrm{TiO}_{2}$-anatase coatings}

The substrates used as starting material for the hydrothermal treatments (HT) were discs of commercially pure titanium (cp Ti grade 2, ASTM F67, Pro-titanium, China) with a diameter of $8 \mathrm{~mm}$, thickness of $2 \mathrm{~mm}$, and grooves of $30 \mu \mathrm{m}$ width after the machining process. For the hydrothermal synthesis (HT) three aqueous suspensions containing Titanium (IV) isopropoxide $\left(\mathrm{Ti}(\mathrm{iOPr})_{4}\right.$, Acros Organics) were prepared. No other additive was used for the first suspension (sample TilV), which had $\mathrm{pH} \approx 5$; the second and third suspensions (samples Ti2V and Ti3V) were adjusted to $\mathrm{pH} \approx 10$ by adding tetramethylammonium hydroxide (TMAH, Sigma-Aldrich Chemie GmbH, Germany). The suspensions were poured into three Teflon vessels containing Ti-discs and, after, in steel autoclaves. All the autoclaves were heated at $200^{\circ} \mathrm{C}$ in the oven (APT.line, Binder $\mathrm{GmbH}$, Germany), but for different times: the first and second suspensions (samples TilV and Ti2V) were treated for $24 \mathrm{~h}$, while the third one (sample Ti3V) for $48 \mathrm{~h}$. The synthesis parameters are summarized in Table 1. Pristine titanium (Ti NT) was used as reference material.

All discs were sterilized in $70 \%$ ethanol $(\mathrm{EtOH}$, Sigma-Aldrich Chemie $\mathrm{GmbH}$ ), carefully washed with sterilized Phosphate Buffer Solution (PBS 10X, pH 7.4, Gibco) and further washed with the culture medium for 6 times in $24 \mathrm{~h}$, before any contact with the cells.

\section{Photofunctionalization of the coatings}

Half of the sample benches were pre-irradiated for $5 \mathrm{~h}$ before the discs came in contact with the cell culture. An UVB portable lamp (Dual $302 \mathrm{~nm}$ Wavelength Light Tubes Lamp, $8 \mathrm{~W}, 2000 \mu \mathrm{W} / \mathrm{cm}^{2}$, Cole-Parmer) was used for the pre-irradiation with a working distance of $\approx 10 \mathrm{~cm}$.

\section{Coating surface characterization}

$\mathrm{TiO}_{2}$-anatase crystal morphology was examined by field-emission-gun scanning electron microscopy (FEG-SEM, Zeiss SUPRA 35VP, Carl Zeiss SMT and JEOL JSM 7600F).

The surface roughness was investigated by atomic force microscope (AFM, DiDimension 3100, Veeco Instruments Inc., CA, USA) on $1 \times 1 \mu^{2}$ areas, to 
Table I. Summary of the hydrothermal treatment $(\mathrm{HT})$ parameters and surface properties for samples Ti NT, TilV, Ti2V, and Ti3V: estimated crystal size was obtained by scanning electron micrographs; the roughness parameters $\left(S_{a}\right.$, surface mean roughness, $S_{q}$, surface root mean square, $S A$, extrapolated surface area) were obtained by AFM imaging on $\mathrm{I} \times \mathrm{I} \mu \mathrm{m}^{2}$ scanned areas; the water contact angle (CA) was measured before (no irr) and after (pre-irr) UVB irradiation for $5 \mathrm{~h}\left(\mathrm{SE} \pm 5^{\circ}\right)$.

\begin{tabular}{|c|c|c|c|c|}
\hline Parameter & Ti NT & TilV & $\mathrm{Ti} 2 \mathrm{~V}$ & Ti3V \\
\hline Additives & - & - & TMAH & TMAH \\
\hline Suspension $\mathrm{pH}$ (before HT) & - & $\mathrm{pH} \approx 5$ & $\mathrm{pH} \approx 10$ & $\mathrm{pH} \approx 10$ \\
\hline HT time & - & $24 \mathrm{~h}$ & $24 \mathrm{~h}$ & $48 \mathrm{~h}$ \\
\hline Estimated crystal size (nm) & - & $30-70$ & $20-50$ & $80-100$ \\
\hline Crystal geometry & - & Irregular & Bipyramidal & Cubic \\
\hline$S_{a}(\mathrm{~nm})$ & $20.3 \pm 3.2$ & $33.2 \pm 0.8$ & $24.6 \pm 3.2$ & $48.6 \pm 2.3$ \\
\hline$S_{q}(\mathrm{~nm})$ & $23.5 \pm 3.5$ & $43.2 \pm 3.2$ & $31.1 \pm 3.8$ & $60.1 \pm 4.1$ \\
\hline$S A\left(\mu \mathrm{m}^{2}\right)$ & $1.0 \pm 0.1$ & $7.1 \pm 0.6$ & $7.4 \pm 0.2$ & $7.9 \pm 1.5$ \\
\hline \multicolumn{5}{|l|}{$\mathrm{CA}$} \\
\hline No irr & $88^{\circ}$ & $84^{\circ}$ & $71^{\circ}$ & $43^{\circ}$ \\
\hline Pre-irr & $65^{\circ}$ & $22^{\circ}$ & $18^{\circ}$ & $11^{\circ}$ \\
\hline
\end{tabular}

avoid the waviness of the substrates derived from the machining process. The mean surface roughness $\left(S_{a}\right)$, the root-mean-square roughness $\left(S_{q}\right)$, and the extrapolated exposed surface area $(S A)$ were calculated on three different areas per sample and the values expressed as mean with their standard error. The measurements were performed before and after the cell tests.

A Theta Lite T101 optical tensiometer (Attension, Biolin Scientific) was used to evaluate the sessile drop contact angles (CA) on the surfaces. The results are presented as the mean of five measurements per sample $\left(\mathrm{SE} \pm 5^{\circ}\right)$. The measurements were performed before and after $5 \mathrm{~h}$ of irradiation of the samples under UVB (302 nm) light.

\section{Cell cultures}

As established previously, ${ }^{19,20}$ human mesenchymal stem cells (hMSCs) were isolated from bone reaming debris of five patients of various age, gender and without any particular clinical condition (Table S1), in order to have a statistically representative human sample. The study design was approved by the Local Ethics Commission (Reference number: 245/13) and all donors of reaming debris provided informed consent. Cells were grown in a humidified atmosphere with $5 \%$ $\mathrm{CO}_{2}$ at $37^{\circ} \mathrm{C}$ in $\mathrm{F} 12 \mathrm{~K}$ Nutrient Mix medium (Life Technologies), supplemented with embryonic stem cells fetal bovine serum (FBS ES, PAN Biotech), and antibiotic solution (Pen-Strept 100x, Life Technologies). At $100 \%$ confluency, the cells were detached using trypsin-EDTA (Life technologies) and re-plated for three passages. At passage no. 3, the cells were detached by trypsinization and seeded onto each Ti-disc (noncoated or coated, no irradiated or preirradiated) in density $4 \times 10^{4}$, previously placed in 24-well plates. The cells for the osteogenic tests were cultured in a differentiation medium, after $48 \mathrm{~h}$ of incubation, composed of $10 \%$ defined fetal bovine serum (FBS gold, PAA Laboratories $\mathrm{GmbH}$ ), $10^{-7} \mathrm{M}$ dexamethasone (Sigma-Aldrich Chemie $\mathrm{GmbH}$ ), $5 \times 10^{-5}$ M (+)sodium L-ascorbate (Sigma-Aldrich Chemie $\mathrm{GmbH}), 10^{-2} \mathrm{M} \beta$-glycerophosphate disodium salt hydrate (Sigma-Aldrich Chemie $\mathrm{GmbH}$ ), antibiotic solution (Pen-Strept $100 \times$, Life Technologies) in Dulbecco's modified eagle medium with low glucose content (DMEM low Glu, Life Technologies). The media of both cultures were renewed every 5 days and 1 day before each harvesting time point. Cultures in empty plate wells were used as control.

\section{Cell viability test}

The cell cultured for MTT (3-[4,5-dimethylthiazol-2-yl]2,5 diphenyl tetrazolium bromide, Sigma-Aldrich Chemie $\mathrm{GmbH}$ ) colorimetric assay were grown for 14 days. The metabolic activity of the cells, cultured on noncoated or $\mathrm{TiO}_{2}$-coated discs, with or without pre-irradiation, was estimated with MTT at the time points 0,7 , and 14 days (d0, d7, d14). At the defined time point, $100 \mu \mathrm{L}$ MTT was added per $1 \mathrm{~mL}$ of medium and the plate was incubated at $37^{\circ} \mathrm{C}$ for $4 \mathrm{~h}$ in dark. Next, the medium was discarded and the MTT formazan salt was dissolved in $1 \mathrm{~mL}$ of lysis buffer $(0.04 \mathrm{~N}$ hydrocloridric acid in 2-Propanol), followed by $10 \mathrm{~min}$ of shaking in dark. The samples were then centrifuged and transferred to a 96-well plate for the absorbance measure at $570 \mathrm{~nm}($ ref. $630 \mathrm{~nm})$ with 
the ELISA reader (Synergy HT, BioTek). The assay was performed in triplet.

\section{Cell differentiation test}

Alkaline phosphatase (ALP) and PicoGreen assays give information about ALP enzyme amount, a mineralization promoter, and DNA quantification, respectively. The cultures were maintained under osteogenic conditions for 28 days, with the time points at $0,7,14$, and 28 days (d0, d7, d14, d28). At each time point, $250 \mu \mathrm{L}$ of Triton X-100 1\% (Sigma-Aldrich Chemie $\mathrm{GmbH}$ ) was added to cells, grown in $1 \mathrm{~mL}$ of medium and the whole plate was frozen at $-80^{\circ} \mathrm{C}$. After defrosting, the suspension containing cells was transferred and centrifuged. For ALP colorimetry, $10 \mu \mathrm{L}$ of the supernatant was transferred in triplicate in a 96-well plate and added with p-NPP (p-nitrophenyl-phosphate) assay buffer $1 \times$ and solution substrate, both contained in the SensoLyte pNPP Alkaline Phosphatase Assay kit (Ana Spec EGT group). After 45 min of incubation at $37^{\circ} \mathrm{C}$, the absorbance was read at $405 \mathrm{~nm}$ with the ELISA reader. For the PicoGreen assay, $5 \mu \mathrm{L}$ of the supernatant was transferred in triplicate in a 96-well plate and added with a solution of PicoGreen reagent and TE Buffer (Quant-iT PicoGreen ds DNA Assay kit, Invitrogen, Molecular Probes), following the producer instructions. The fluorescence was measured at $485 / 20 \mathrm{~nm}$ and $528 / 20 \mathrm{~nm}$ with the ELISA reader.

\section{Calcium ions uptake}

The calcium ions $\left(\mathrm{Ca}^{2+}\right)$ uptake from the culture medium was checked for the cultures in osteogenic conditions, with time points at $0,7,14,21$, and 28 days $(\mathrm{d} 0, \mathrm{~d} 7, \mathrm{~d} 14, \mathrm{~d} 21, \mathrm{~d} 28)$, by using an electrolyte analyzer (9180, Roche).

\section{Cell imaging}

The cell cultures were regularly checked under inverted optical microscope (Axiovert 10, Carl Zeiss) and pictures at the edge of each disc were recorded every second day and before any assay.

After $7 \mathrm{~d}$ of culturing in osteogenic conditions, the hMSCs were fixed for $10 \mathrm{~min}$ in $4 \%$ paraformaldehyde (Roth) and stained using fluorescent dyes, i.e. DAPI blue for the nuclei (Roth) and phalloidin-tetramethylrhodamine red for the actin filaments (TRITC, SigmaAldrich Chemie $\mathrm{GmbH}$ ). Fluorescent microscope (IX81, Olympus) was used to qualitatively examine the cell morphology.

After $7 \mathrm{~d}$, the cultures in osteogenic media were also observed under FEG-SEM (Zeiss SUPRA 35VP, Carl
Zeiss SMT, and JEOL JSM 7600F). The specimens were previously fixed for $10 \mathrm{~min}$ in $4 \%$ paraformaldehyde and sputter-coated with carbon.

\section{Statistics}

All statistical analyses were performed with the IBM SPSS Statistics 20 software and the equality of mean values was compared at a confidence interval of $95 \%$ $(p<0.05)$. The 1 -sample Kolmogorov-Smirnov test was applied to verify the data distribution, followed by the ANOVA test or the K-independent samples Kruskal-Wallis and 2-independent samples MannWhitney tests. Bivariate correlation (Pearson correlation coefficients) was also employed.

\section{Results}

\section{Coating surface characterization}

The three synthesis procedures produced three variants of $\mathrm{TiO}_{2}$-anatase coatings ( $\mathrm{Ti} 1 \mathrm{~V}, \mathrm{Ti} 2 \mathrm{~V}, \mathrm{Ti} 3 \mathrm{~V}$ ). As shown in Figure 1, the crystal morphology differed from an irregular crystal shape in sample TilV to a cubic-like structure for samples Ti2V and Ti3V, with much squared crystals and (001) exposed facets in the last one.

Due to the different nanostructure of the three coatings, the nanoroughness also differed from one sample to another. The surface roughness values obtained by AFM (Table 1) showed a trend which follows the crystal size $(\mathrm{Ti} 2 \mathrm{~V}<\mathrm{Ti} 1 \mathrm{~V}<\mathrm{Ti} 3 \mathrm{~V})$. The sample TilV was statistically different from Ti NT in terms of $S_{q}$, while the sample Ti3V was statistically different from Ti2V and Ti NT in terms of both $S_{a}$ and $S_{q}$. All the HTsamples were statistically different from $\mathrm{Ti}$ NT in terms of exposed surface area. The cell contact with the surfaces did not modify the topography or destroy the crystal structure and, therefore, no difference was found between the roughness values obtained before and after the cell tests.

Surface wettability and photo-induced wettability were determined on nonirradiated (no irr) or UV preirradiated (pre-irr) surfaces. The hydrothermal treatment improved the surface hydrophilicity by reducing the contact angle (CA) compared to the bare titanium (Ti NT); the drop in CA was even more evident when the HT-samples were pre-irradiated, showing a reduction of CA values by $-75 \%$ when comparing all the irradiated HT-coatings with the nonirradiated ones. When Ti NT coating was irradiated, $25 \%$ decrease in CA was observed; this might be due to the fact that irradiation occurred in liquid, ${ }^{13}$ which rendered the amorphous titania layer more hydrated and, therefore, more hydrophilic. After irradiation the sample Ti3V 

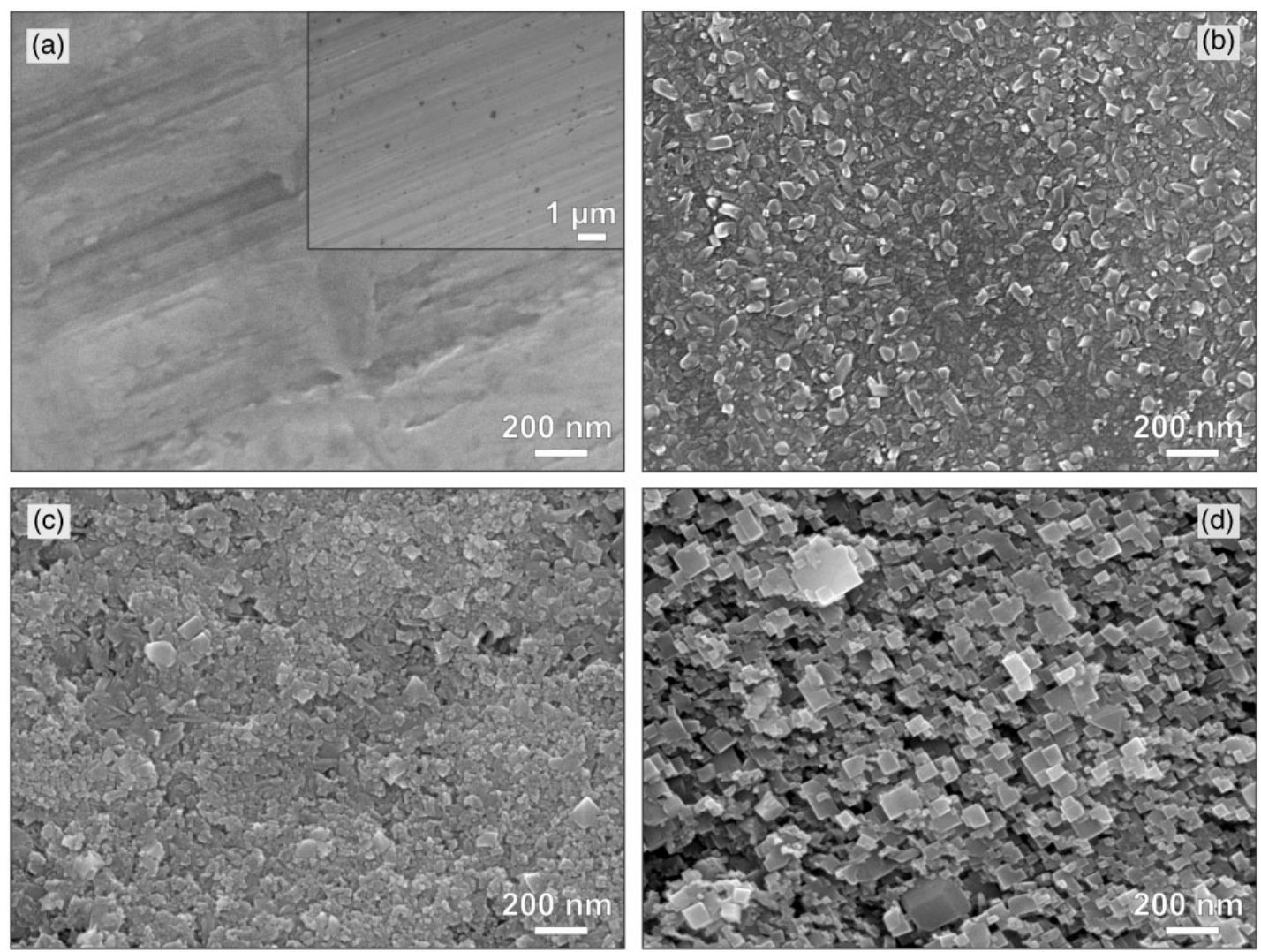

Figure I. FEG-SEM micrographs of sample: (a) Ti NT (machined); (b) TilV (estimated nanocrystal size: 30-70 nm); (c) Ti2V (estimated nanocrystal size: $20-50 \mathrm{~nm}$ ); (d) Ti3V (estimated nanocrystal size: $80-100 \mathrm{~nm}$ ).

behaved as superhydrophilic $\left(\mathrm{CA}=11^{\circ}\right){ }^{11}$ The results are summarized in Table 1.

Finally, while the UV-irradiation of the HT-coatings did not modify the surface morphology or topography, it influenced the physico-chemical surface properties, as previously shown in Lorenzetti et al. ${ }^{17,18}$

\section{Cell viability test}

The results obtained by the MTT assay (Figure 2) showed that the hMSCs can grow and proliferate on HT anatase coatings (no significant difference with the cell plate control). No significant difference was found within the sample groups (HT Ti\#V vs. Ti NT); moreover, no significant difference of viability was observed due to the UV treatment (no irr vs. pre-irr). Furthermore, the cell contact with the HT coatings, with or without UV pre-irradiation, did not affect the cells viability or the normal culture growth under standard conditions.

\section{Cell differentiation test}

According to alkaline phosphatase (ALP) signal, osteogenic medium stimulated the plated cells towards the differentiation into an osteoblast lineage, as the signal almost doubled if $\mathrm{d} 7$ and $\mathrm{d} 14$ were compared with the control results (Figure 3). The samples Ti1V and Ti2V showed an increase of ALP production from d7 to d14; then a minor but not significant ALP amount was revealed at $\mathrm{d} 28$ when nonirradiated, while a constant increasing tendency was observed in case of the preirradiated samples (d28). Ti3V gave the maximum ALP signal among the Ti variants in both tested conditions, displaying the highest ALP signal in comparison with the other used substrates.

\section{Calcium ions uptake}

The $\mathrm{Ca}^{2+}$ consumption from the culture medium was used to assess the osteogenic activity. Comparing the nonirradiated samples, Ti3V revealed to be the most osteogenic, followed by TilV, Ti2V, and Ti NT, respectively. The cells seeded on the photo-activated substrates strongly increased the $\mathrm{Ca}^{2+}$ uptake; all the pre-irradiated discs displayed a significantly higher $\mathrm{Ca}^{2+}$ uptake in comparison with the cell plate control (pre-irradiated Ti NT, Ti2V, and Ti3V groups significantly different vs. control plate) and the nonirradiated correspondents (Ti NT no irr vs. Ti NT pre-irr, TilV no 


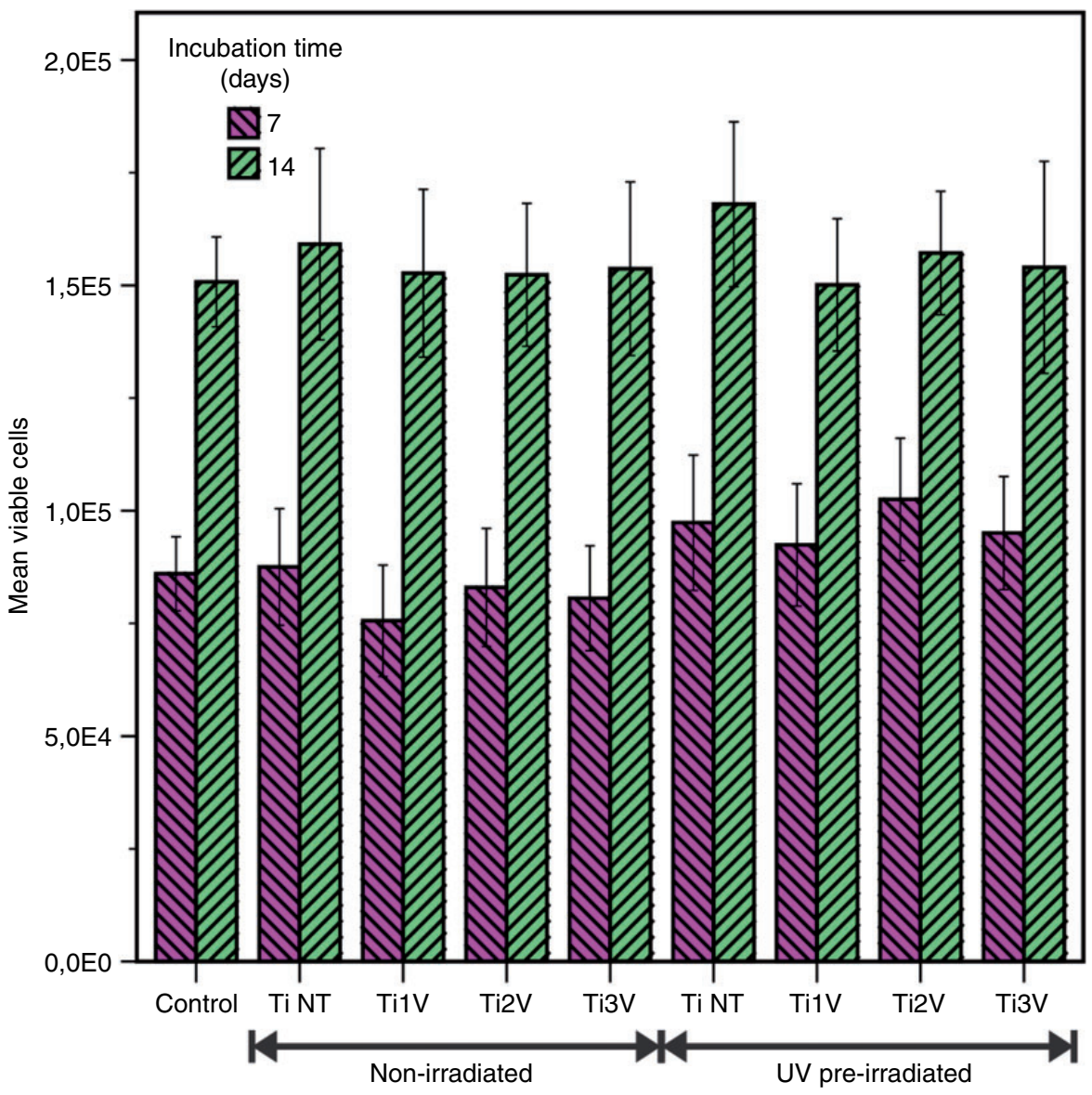

Figure 2. Viability of hMSCs in standard conditions at 7 days (d7) and I4 days (dI4) after seeding onto nonirradiated and UV pre-irradiated surfaces: cell plate (control), titanium nontreated (Ti NT), and hydrothermally treated variants TilV, Ti2V, and Ti3V.

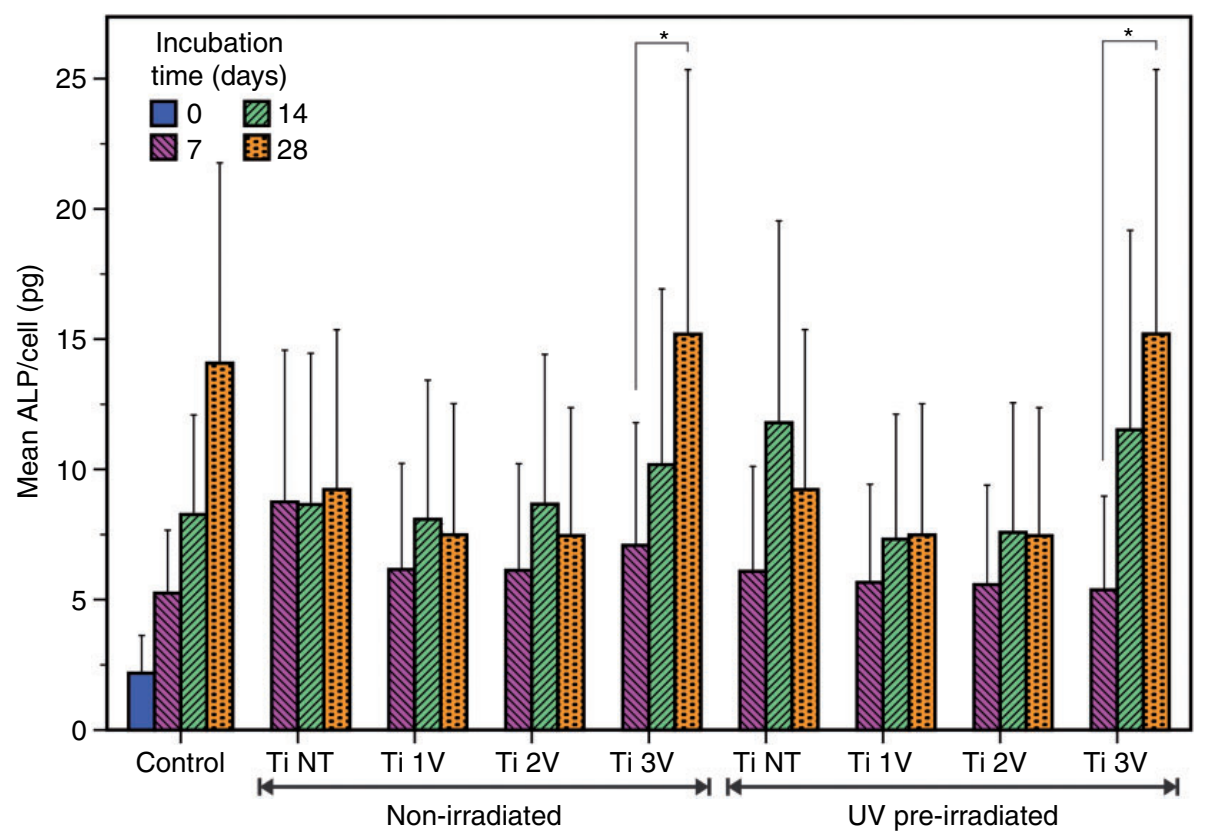

Figure 3. Differentiation of hMSCs in osteogenic conditions obtained from alkaline phosphatase (ALP) and PicoGreen assays at 0,7 , 14 , and 28 days ( $\mathrm{d} 0, \mathrm{~d} 7, \mathrm{dl} 4$, and $\mathrm{d} 28$ ) after seeding onto nonirradiated and $\mathrm{UV}$ pre-irradiated samples: cell plate (control), titanium nontreated (Ti NT), and hydrothermally treated variants TilV, Ti2V, and Ti3V. $* p<0.05$, statistically significant difference. 


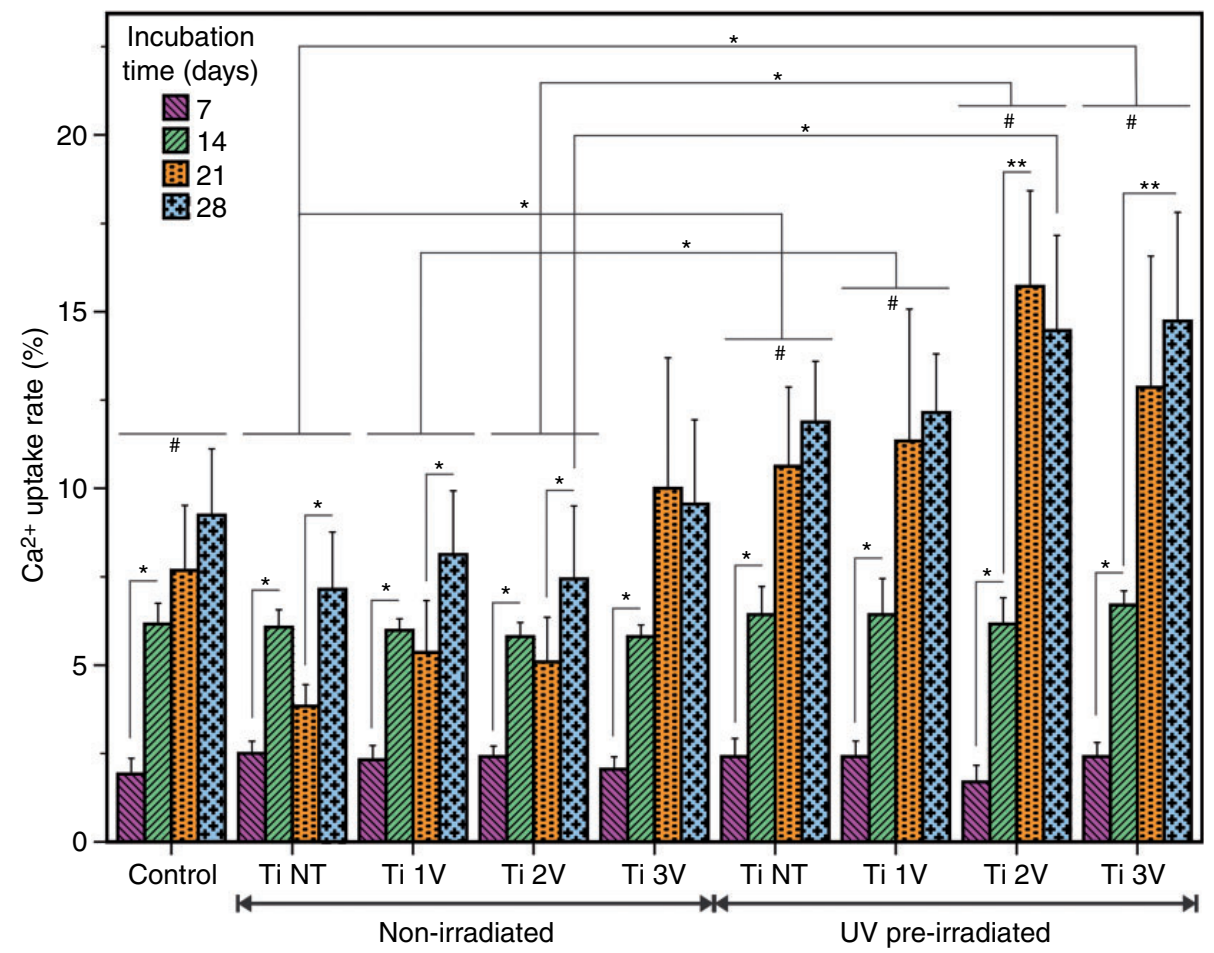

Figure 4. Calcium ions uptake (\%) of hMSCs in osteogenic conditions at $0,7,14,21$, and 28 days (d7, dl4, d2 I, and d28) after seeding onto nonirradiated and UV pre-irradiated samples: cell plate (control), titanium nontreated (Ti NT), and hydrothermally treated variants TilV, Ti2V, and Ti3V. Statistically significant differences: $*_{p}<0.05$ between two samples or two groups, $* * p<0.0 \mathrm{I}$ between two samples, ${ }^{\#} p<0.05$ between one group of samples and the control group.

irr vs. TilV pre-irr, Ti2V no irr vs. Ti2V pre-irr). The pre-irradiated Ti2 $\mathrm{V}$ and Ti3V showed the best osteogenic activity, followed by TilV and Ti NT.

\section{Cell imaging of osteogenic cultures}

Fluorescent microscopic images of hMSCs at d7 in osteogenic conditions showed that the cells were able to grow within the grooves of the machined Ti NT and had spindle, elongated shape with parallely arranged actin fibers (Figure 5(a)); the cells on HT samples were more spread and randomly distributed (Figure 5(b)) and presented lamellipodia structures. When Ti NT pre-irr samples were used, the cells started to interconnect also across the disc grooves (Figure 5(c)) and appeared larger, in comparison with Ti NT no irr sample. A thicker carpet of overlapping cells was observed on all the HT pre-irradiated variants (Figure 5(d)).

The scanning electron micrographs at $\mathrm{d} 7$ (Figure 6) revealed that the cells well spread along the nanostructured $\mathrm{TiO}_{2}$ coatings, with extrusions well adhered and branched into the nanopores between the crystals. However, the cells grown on the pre-irradiated HT Ti-variants exhibited a similar morphology but superior features, especially filopodia (Figure 6(c) and (d)), compared with the nonirradiated ones (Figure 6(a) and (b)), with more pseudopodia.

The cell cultures were also inspected with inverted optical imaging, taken at the edges of the discs (Figure 7). At $\mathrm{d} 0$, the cell density was consistently higher around the perimeter of UV pre-irradiated substrates (Figure 7(c)) with respect to the nonirradiated ones (Figure 7(b)) and Ti NT no irr (Figure 7(a)). Comparing the osteogenic development of the cultures (Figure 7(d) to (i)) at different time points, a premature differentiation and mineralization occurred earlier when UV pre-irradiated HT Ti\#V (Figure 7(f)) were used rather than nonirradiated Ti NT (Figure 7(d)) and HT Ti\#V (Figure 7(e)). The same trend was observed for the mineralization process at $\mathrm{d} 14$, if the HT Ti\#V samples (Figure 7(i)) are compared to the nonirradiated (Figure 7(h)); the Ti NT no irr presented the least mineralization development. At d28, bone-like nodules (at various level of development) appeared on both nonirradiated and pre-irradiated HT discs (Figure 8(a) and (b)). In general, pre-irr Ti NT did not show visible differences compared to the no-irr Ti NT.

The results suggest that the HT nanostructured substrates were more favorable for hMSCs development and differentiation than the Ti NT substrates. 

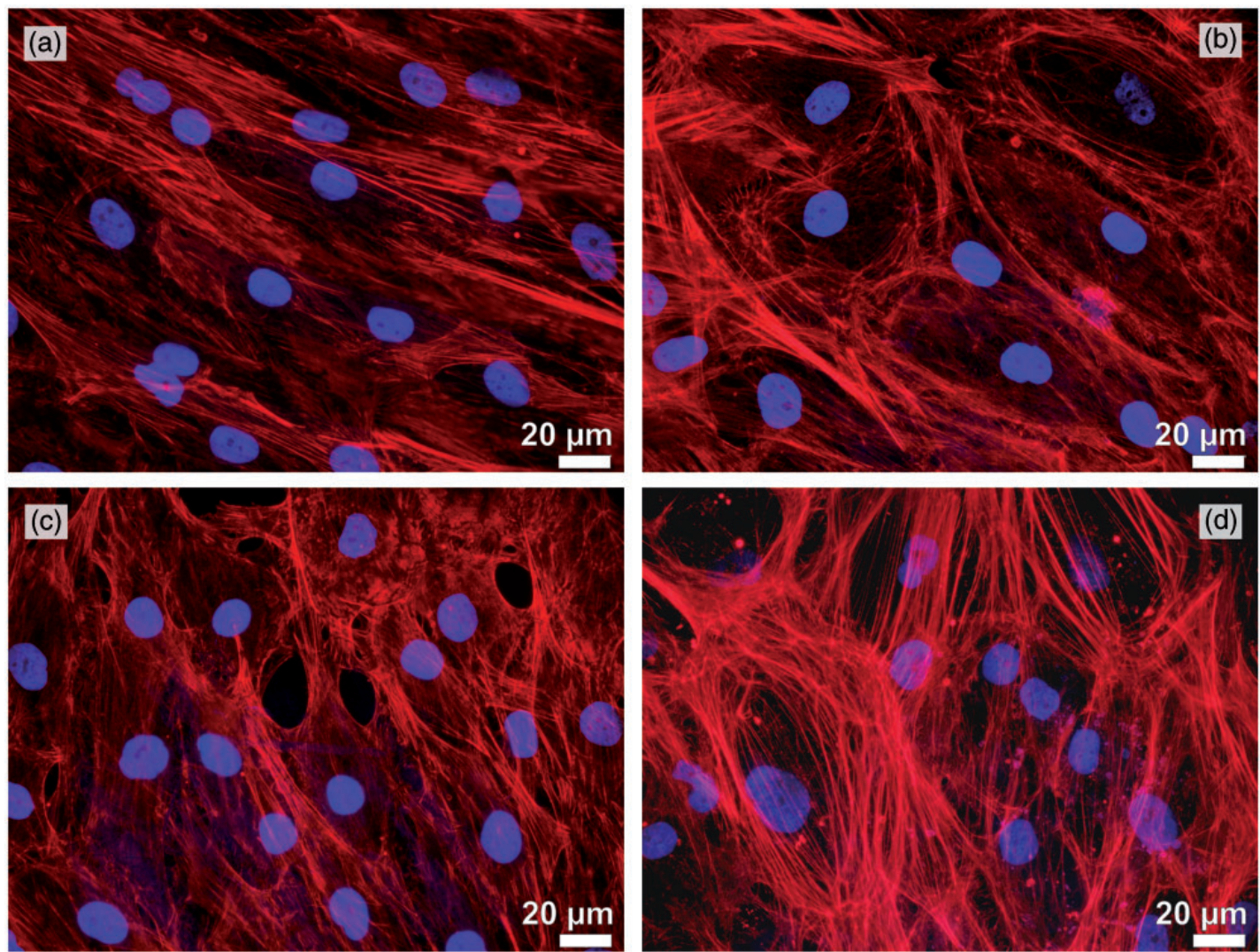

Figure 5. Fluorescent microscope images of ZK36 cells in osteogenic conditions at day 7 after seeding onto: (a) Ti NT no irr; (b) Ti3V no irr; (c) Ti NT pre-irr; (d) Ti3V pre-irr. The cell nuclei are stained with DAPI blue, while the actin filaments with phalloidin-tetramethylrhodamine red.

\section{Discussion}

The medical market has a request for new Ti-based implants for hard tissue replacement with improved bioactivity and shorter wound healing time and that was at the basis of the current study. The application of hydrothermal treatment on titanium discs led to the synthesis of nanocrystalline $\mathrm{TiO}_{2}$-anatase coatings ${ }^{18}$ with different surface properties (mainly topography and crystal morphology, wettability, and photoinduced wettability), which are known to modulate the behavior of the cells. ${ }^{2,3}$ Mindful of our past results about the photo-induction phenomena, ${ }^{18}$ the effect of UVB pre-irradiation on the proliferation, activity and osteogenesis of the cell cultures in contact with three $\mathrm{HT}_{-} \mathrm{TiO}_{2}$ variants (Ti1V, Ti2V, and Ti3V vs. Ti NT) was analyzed. According to the streaming potential measurements, all three HT variants had negative surface charge at physiological $\mathrm{pH}$, ranging from about $-65 \mathrm{mV}$ to $-55 \mathrm{mV}$ in $0.001 \mathrm{~mol} / 1 \mathrm{PBS}^{21}$ The HT samples showed a trend within the nano-roughness parameters $(\mathrm{Ti} \mathrm{NT}<\mathrm{Ti} 2 \mathrm{~V}<\mathrm{Ti} 1 \mathrm{~V}<\mathrm{Ti} 3 \mathrm{~V}$ ) in accordance to the crystal size of the coatings (Table 1) and, consequently, might be taken into account. Moreover, the samples differed in the crystal dimensions and morphology (Figure 1), thus, also in the distinctive wettability and response to UV activation (denoted by the photoinduced hydrophilicity).

Primary human mesenchymal stem cells (hMSCs) from five healthy patients were preferentially chosen as model cells for the in vitro study, as they are able to differentiate in osteoblasts under certain stimuli. ${ }^{19,22}$ Working with primary cells resulted in a high standard deviation (Figure S1). However, the high variability gave an extended representation of the random variance which can be expected within the real population.

\section{hMSCs under standard conditions}

The metabolic activity was estimated by the MTT assay. The produced formazan salt reflects the mitochondrial activity of the cells, thus, indirectly, the cell viability. The presence of different $\mathrm{TiO}_{2}$ coatings, with or without UV pre-irradiation, did not alter the cell proliferation within the 14 days of culture. The firmly attached $\mathrm{HT}-\mathrm{TiO}_{2}$ crystals allowed cell growth comparable with the one obtained on the control plate. hMSCs could grow on surfaces with a vast scale of wettability, 

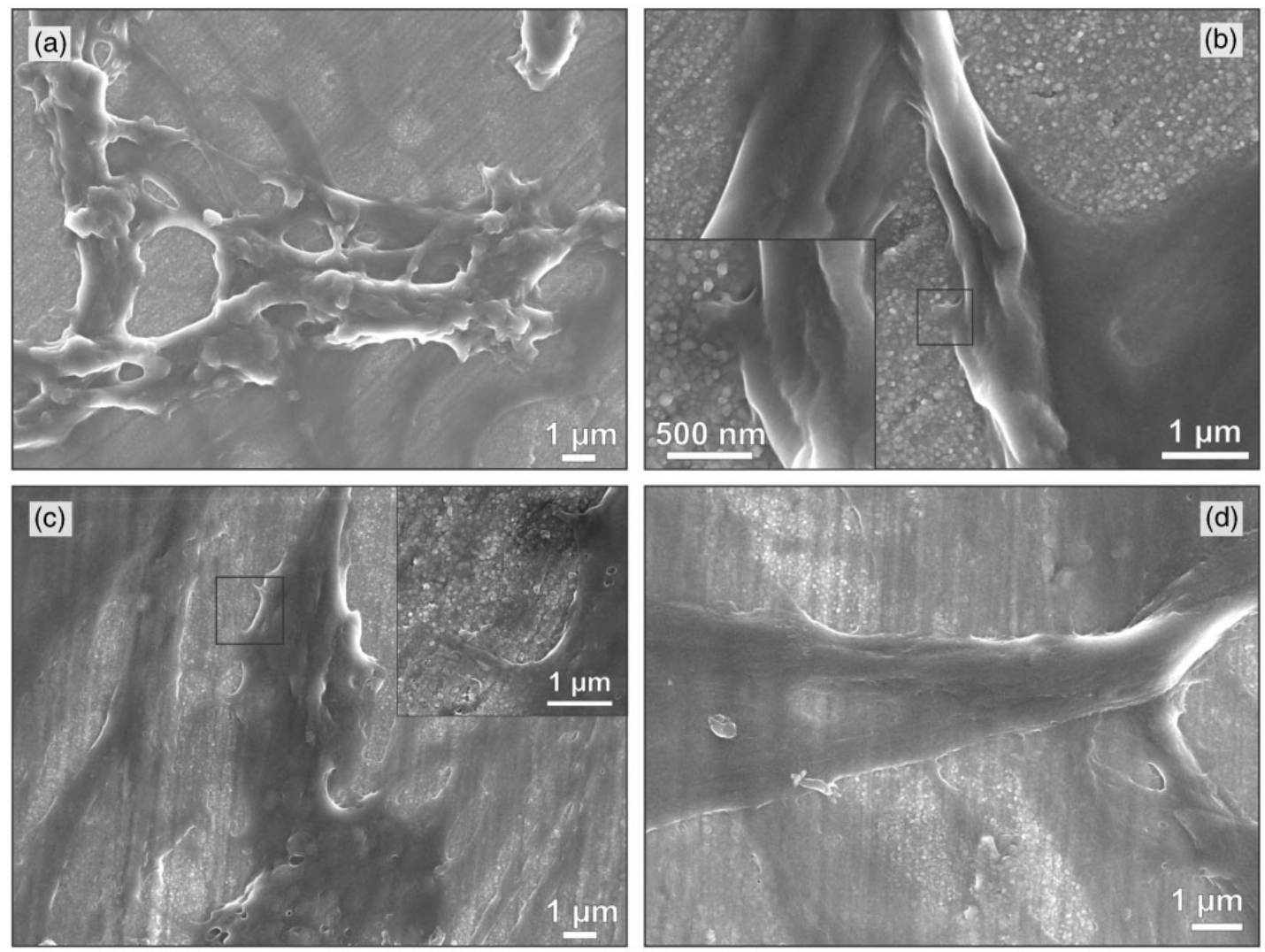

Figure 6. FEG-SEM micrographs at different magnifications of ZK36 cells after 7 days of culture in osteogenic conditions adhered on: (a, b) TilV no irr; (c, d) TilV pre-irr. (Inset b) Pseudo-podia extrusions branched to the not irradiated substrates. (Inset c) Filopodia extrusions branched to the pre-irradiated substrates.

ranging from a quasi-hydrophobic (Ti NT and TilV no irr) to superhydrophilic surfaces (Ti3V pre-irr). Moreover, cell growth was not influenced by the different topographies of $\mathrm{Ti} \mathrm{NT}$ and $\mathrm{Ti} \# \mathrm{~V}$, as reported also by Dumas et al. ${ }^{23}$ The biological dilemma on the indirect correlation between proliferation and differentiation rates is still under debate: ${ }^{24,25}$ when the cells start to differentiate, the proliferation slows down. This could be the reason for no statistical differences in proliferation among the Ti-variants.

\section{hMSCs under osteogenic stimulus}

Cell differentiation and osteogenesis. Under osteogenic culture conditions, immediately at $0 \mathrm{~d}$ the cells appeared in close contact with the side of the photofunctionalized discs (Figure 7(c)), proven by a higher cell density in comparison with the nonirradiated ones (Figure 7(b)) and Ti NT (Figure 7(a)). An early-stage differentiation tendency of hMSCs was observed already at d5, especially on the HT variants (Figure 7(e) and (f)) rather than on Ti NT (Figure 7(d)). At d7, when cultured on noncoated discs, the cells had a spindle shape (Figure 5(a)), but underwent morphological changes on HT samples (Figure 5(b)) and pre-irr HT samples (Figure 5(d)). In general, cells can recognise the surface topography and align to it using filopodia, following the so-called "contact guidance phenomenon". ${ }^{26,27}$ This is clear for Ti NT, whose surface presented defined micro-grooves due to the machining: the cells appeared to lie within the grooves and took an elongated morphology (Figure 5(a)). On the other hand, it seems that the titania nanostructured surfaces, with or without photoactivation, positively enhanced the development of hMSCs, showing a branched shape and a more complex actin filament network (Figure 5(b) and (d)). The architecture of actin cytoskeleton is crucial for the maintenance of cell shape and cell adhesion. ${ }^{28}$ The different cell morphologies (i.e. spindle or branched) can be a function of the cell adhesion level to the substrate. ${ }^{2}$ As suggested in Rosales-Leal et al., ${ }^{29}$ at constant surface chemistry, the topographical features can affect the cell adhesion and proliferation. The enhanced level of actin organization and cytoskeletal development on the nanostructured $\mathrm{TiO}_{2}$-coated substrates, rather than on Ti NT no irr, confirms the active role of surface roughness for the cell development. In fact, the nanostructures provided much higher exposed surface area than 


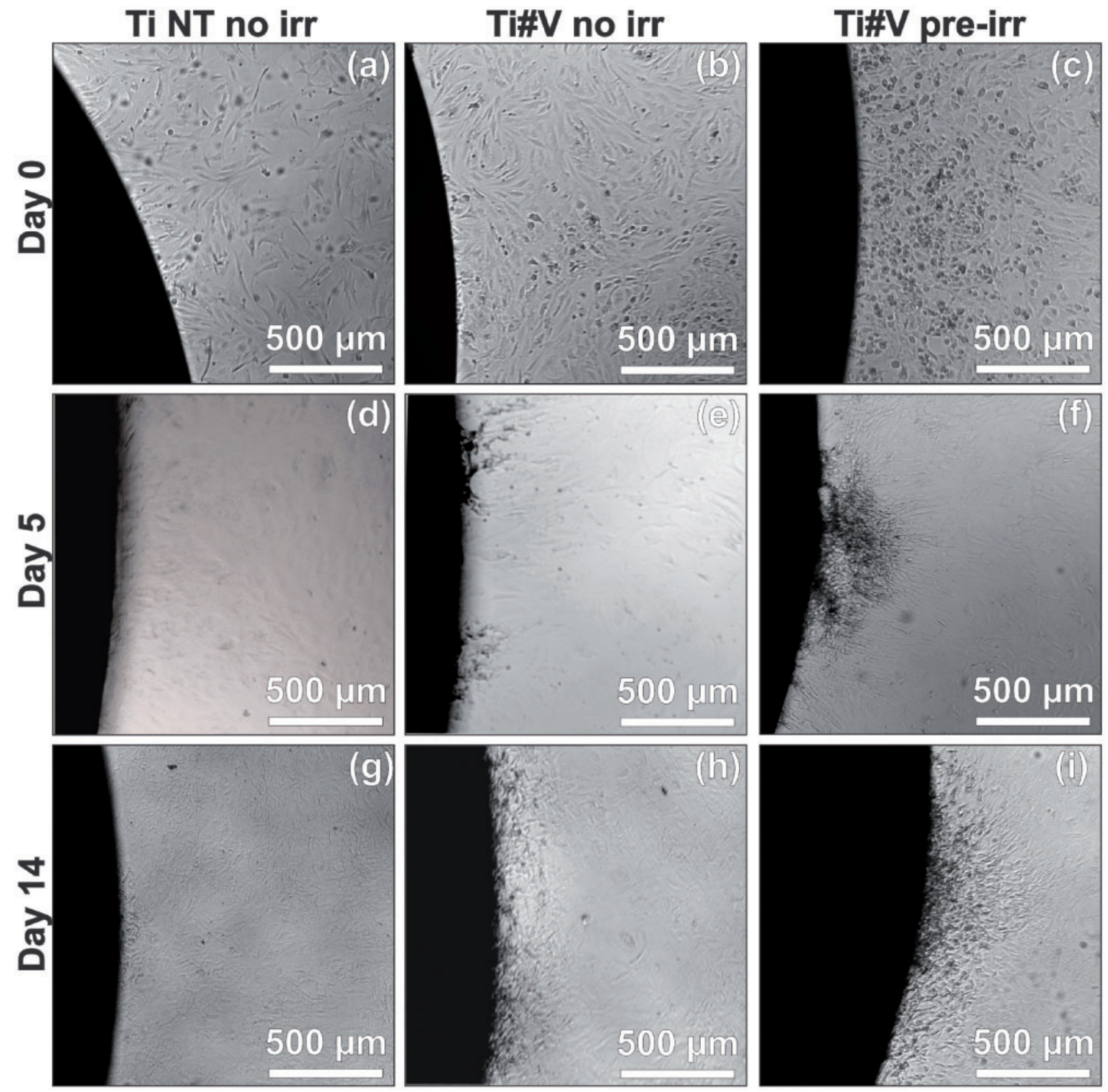

Figure 7. Cell imaging by inverted optical microscope of ZK79 cells: cells approaching the edge of the discs at day 0 for samples: (a) Ti NT no irr, (b) Ti3V no irr, and (c) Ti3V pre-irr; different stages of mineralization of ZK79 cells seeded on samples: (d, g) Ti NT no irr, (e, h) TilV no irr and (f, i) TilV pre-irr at day 5 and at day 14 , respectively.
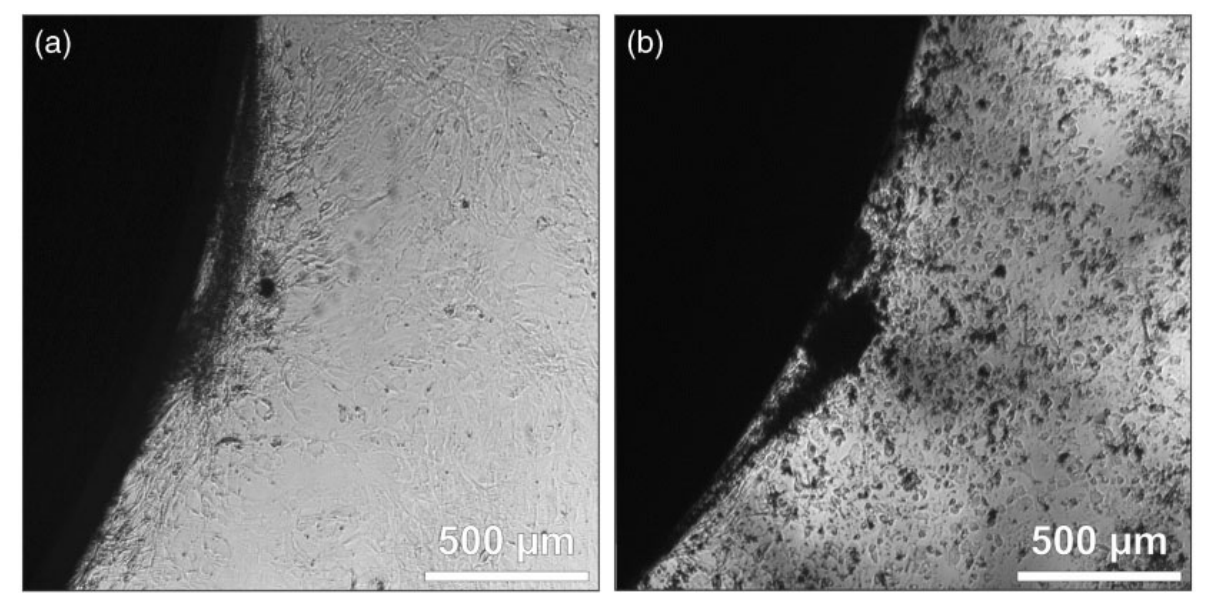

Figure 8. Cell imaging by inverted optical microscope: bone-like nodules formation at day 28 on samples: (a) TilV no irr; (b) Ti2V pre-irr. 
Ti NT and allowed a deep branching of the cell pseudopodia (Figure 6(a) and (b)) and filopodia (Figure 6(c) and (d)) into the "nanopores" within the $\mathrm{TiO}_{2}$-crystals.

Besides the surface roughness, cell adhesion is known to be influenced by wettability, ${ }^{30,31}$ since the latter is closely related to the surface energy. Several studies reported that a greater biological behavior was found on hydrophilic titanium surfaces rather than on hydrophobic ones. ${ }^{32-34}$

The differentiation of the hMSCs in osteoblast was verified by the expression of ALP, a metalloenzyme fundamental in the initial phases of mineralization of hard tissues. ${ }^{35}$ As pointed out by Zhao et al., ${ }^{33}$ the retention of high surface energy enhances the expression of ALP and osteocalcin of osteoblast-like cells, since chemically pure and hydrophilic surfaces have a high hydroxylation/hydration rate. During the cell proliferation and mineralization stage, the ALP production considerably increases, while in heavily mineralized cultures the ALP expression is down-regulated and the cellular levels decline. ${ }^{36,37}$ This mechanism was observed also in the present study (Figure 3), where the ALP activity was higher at $\mathrm{d} 14$ than at $\mathrm{d} 7$ for all the nonirradiated HT samples, reaching a plateau in $\mathrm{ALP} /$ cell content almost constant till d28. The cell culture on nonirradiated Ti3V behaved as an exception, displaying a continuous, significant increase of ALP levels till $\mathrm{d} 28$. The premature differentiation indeed led to an earlier osteogenesis (d14), proven by the formation of a thick crown at the edges of the HT-discs, composed of closely adhered cells and newly synthesized mineral nuclei (Figure 7(h) and (i)); also, the mineral phase formed at the UV pre-irradiated HT-discs (Figure 7(i)) appeared not only quantitatively, but also qualitatively improved in respect to the nonirradiated substrates (Figure 7(f)). It was reported that the osteoblast differentiation peaks just before the matrix mineralization begins. ${ }^{33}$ The calcium ions $\left(\mathrm{Ca}^{2+}\right)$ uptake by the cells from the culture medium is the sign of their osteogenic activity, i.e. their ability to form calcium phosphates in order to (re)generate new bone in vivo. The result of calcium ion uptake is in accordance with the trend observed in the ALP production: the mesenchymal stem cells started to differentiate in osteoblasts, especially around 14 days of culture, and then they started to be osteogenically active. The drop in ALP production at $\mathrm{d} 28$ for TilV no irr and Ti2V no irr (Figure 4) indicated the maturation in osteoclasts. Thus, as expected from the ALP production, the $\mathrm{Ca}^{2+}$ uptake for the nonirradiated variants increased significantly after the first 7 days of culture, stayed almost constant at $\mathrm{d} 14$ and $\mathrm{d} 21$ time points and then rose up again at $\mathrm{d} 28$. For the cells cultured on preirradiated substrates, their $\mathrm{Ca}^{2+}$ ions uptake improved at each time point. Likewise, the development of bigger bone-like nodule structures was enhanced on UV preirradiated HT discs (Figure 8(b)), even though it occurred on nonirradiated samples as well (Figure 8(a)). Once again, Ti3V displayed a different behavior, with a peak in calcium ions uptake already at $\mathrm{d} 21$, in accordance with its cell activity. Since nanoand micro-rough surfaces can be also nonwettable, ${ }^{38}$ we assumed that the superior performance of the nonirradiated Ti3V was due to the highest hydrophilicity and nanoporosity (surface exposed area) among the discs.

Importance of the photo-induced surface properties. Due to the irradiation with appropriate UV rays, the outer surface of the nanocrystalline anatase HT-coatings experienced two different photo-induced events, i.e. photocatalysis and photo-induced wettability. ${ }^{18}$ The latter phenomenon concerns the formation of a metastable outermost layer, rich in hydroxyl groups $\left(\mathrm{OH}^{-}\right)$. The phenomenon results in a super-hydrophilic condition, ${ }^{10,11}$ which is retained up to two weeks on the HT-coated samples in dark. ${ }^{18}$ The attained physicochemical condition of Ti-based implants after UV irradiation was recently renamed "photofunctionalization". ${ }^{15}$ It is considered to reverse the time-dependent titanium "biological aging", i.e. the recovery of the initial status of wetting and organic (hydrocarbon) contamination of the surface. ${ }^{39}$ Generally, a considerable hydrophilicity has been hypothesized to be beneficial for the implant surface osseointegration during the early stage of wound healing. As soon as the implant is inserted in the body, the formation of a water molecule layer along the whole surface of the implant occurs within nanoseconds, in order to facilitate the further reactions between biological components and material. ${ }^{40} \mathrm{~A}$ high surface energy is desired to improve hydrophilicity and, consequently, to increase the adherence of the protein conditioning film, the cell layer and cell spreading. ${ }^{41}$ Accordingly, photofunctionalized titania should result in beneficial biological effects. However, the photo-induced phenomenon depends on the wavelength and power of the light source. A range of surface hydrophilicity and surface hydrocarbon decontamination are reached by using different conditions of irradiation, i.e. UVA or UVC, and illumination times. Gao et al. ${ }^{16}$ recently reported higher cell proliferation on micro-arc oxidized titanium irradiated by UVC light (superhydrophilic) rather than by UVA light (hydrophilic) if $24 \mathrm{~h}$ irradiation was used. They assumed that the enhanced biological activity was due to photolytic activity (direct hydrocarbon disruption) under UVC rather than photocatalytic activity. Aita et al. ${ }^{15}$ and Iwasa et al. $^{42}$ also agreed that the level of carbon contamination of the surface influenced the cell absorption more than the hydrophilicity level. Ogawa's group $^{39,43,44}$ proposed a model to interpret the 
mechanism behind, based on the variation of the electrostatic properties of the UV-treated surfaces. The researchers claim that the electropositive charges are formed on Ti-surface under UV irradiation. The positive charges should allow the attraction of negatively charged proteins and cells, thus, the electropositivity could be the primary factor for the enhanced bioactivity, rather than the level of hydrophilicity. ${ }^{43}$ As pointed out in Hori et al., ${ }^{45}$ the contribution of hydroxylated/ hydrated $\mathrm{TiO}_{2}$ surfaces to the biological behavior may differ depending on the hydrophilic status and on the involvement of other concomitant surface properties. In order to better understand this contentious topic, in the current study we propose a different approach to photofunctionalize the surface. We used a UVB light at $302 \mathrm{~nm}$ as it poses intermediate energy between the UVA and UVC ranges. The irradiation time was significantly reduced down to $5 \mathrm{~h}$, which is, in our opinion, more practical for the surgical application point of view.

We recently demonstrated by surface streaming potential studies $^{21}$ that after irradiation of the HT-anatase coatings the amount of hydroxyl groups on the surface was strongly enhanced; moreover, Han et al. ${ }^{13}$ reported that the amount of negatively charged, basic Ti-OH groups after UV irradiation was increased and the treatment helped the apatite-forming ability of the SaOS- 2 cell adhesion on micro-arc oxidized Ti-surfaces. In accordance with Tengvall and Lundstrom, ${ }^{46}$ the creation of a highly hydroxylated surface improved the HT-coating reactivity with the surrounding ions, proteins and cells. Calcium is the most important ion, involved in surface-tissue contact, as it was found to form bridging-bonds between the surface and proteins/ cells. ${ }^{44,47}$ According to these findings, we can assume that the calcium uptake was improved when UV $\mathrm{OH}^{-}$-rich surfaces were used, so that a higher formation of hydroxyapatite and mineral phase was allowed. Hence, UVB photo-activation of $\mathrm{HT}-\mathrm{TiO}_{2}$ coatings boosted the bioactivity of the titanium substrate in terms of osteogenesis. Statistical correlation studies about ALP-Ca ${ }^{2+}$ uptake and wettability- $\mathrm{Ca}^{2+}$ uptake showed that there was a direct (Pearson's coefficient: $0.593, p<0.0001)$ and indirect correlation (Pearson's coefficient: $-0.233, p<0.0001$ ), respectively. Therefore, the lower the contact angle values are (very hydrophilic surfaces), the more ALP activity was present (so the cells were more differentiated and active) and the more calcium ions were incorporated by cells to promote mineralization. On the other hand, the bivariate correlation tests between the roughness parameters and the ALP/cell or the $\mathrm{Ca}^{2+}$ uptake values did not show any significant correlation. Accordingly, the roughness effect has to be considered of minor importance in comparison to the surface hydrophilicity.
In general, the samples with the highest nanoroughness and photo-induced hydrophilicity (Ti3V) resulted in the highest osteogenic ability. In particular, the statistical difference between the sample Ti3V pre-irr and the Ti NT no irr in terms of $\mathrm{Ca}^{2+}$ uptake suggests that the UV pre-irradiation did help during the osteogenesis process. Taken all together, this points out how the photo-induced enhancement of $\mathrm{OH}^{-}$group content on the titania surfaces, the derived high surface energy (hydrophilicity), and the electrostatic interactions between $\mathrm{UV} \mathrm{TiO}_{2}, \mathrm{Ca}^{2+}$ ions, proteins and cells, were critical but positive factors in determining the bioactivity of the titanium implants. Last but not least, the relatively long-term stability of the photoinduced hydrophilic character (up to 2 weeks) of the $\mathrm{HT}-\mathrm{TiO}_{2}$ coatings $^{18}$ is expected to be enough protracted to inhibit a fast hydrocarbon contamination of the surface and the consequent aging, and to allow a good biological response in the first stage of wound healing.

Although photo-induced wettability, photocatalytic activity and photolysis are three different mechanisms, we believe the use of UVB light for the photofunctionalization might combine the positive effects of both UVA and UVC lights, having intermediate characteristics of the two ultraviolet edges.

\section{Conclusion}

We tried to investigate how does the photofunctionalization by a relatively short ( 5 hours) UVB irradiation influence the osteogenesis of nanostructured $\mathrm{TiO}_{2}$-anatase coatings, hydrothermally grown on titanium substrates.

The HT treatment provided favorable nanoroughness and higher exposed surface area, as well as greater hydrophilicity, compared to the native amorphous oxide on titanium; the UVB irradiation supplied an enrichment of hydroxyl groups on the surface by the photo-induced hydrophilicity phenomenon. Although differently prepared $\mathrm{HT}-\mathrm{TiO}_{2}$ coatings showed different surface characteristics, the simultaneous advantages given by the combination of HT treatment and UVB irradiation led to an earlier differentiation of primary hMSCs and a greater osteogenesis than nontreated samples. The hMSCs seeded on the pre-irradiated coatings displayed better ability to form a well-arranged mineral phase, in the form of bone-like nodules. Thus, it appeared that the cell behavior was mostly influenced by the surface hydrophilicity and, partially, also by the nanoroughness. In particular, as the characteristics of the oxide coating affect the biological capability, the Ti3V surface displayed a superior cell activity and enhanced osteogenesis among all the samples throughout the entire experiment. 
Despite the limitations of the in vitro studies, it can be expected that the combination of hydrothermally prepared nanocrystalline anatase coatings with the photofunctionalization process would result in a faster wound healing and a tighter bone-to-implant contact in vivo in perspective of application. Additionally, it can be hypothesized that a prolonged irradiation time would produce even more accentuated biological effect, comparable with the reports where a long irradiation time (24-48 h under UVA or UVC light) was used.

\section{Acknowledgement}

The authors wish to thank Mr M Shahid Arshad for the AFM measurements and Dr Matej Skočaj for his valuable comments.

\section{Declaration of conflicting interests}

The authors declared no potential conflicts of interest with respect to the research, authorship, and/or publication of this article.

\section{Funding}

Funding by the European Commission within the framework of the FP7-ITN network BioTiNet (FP7-PEOPLE-2010-ITN264635) is acknowledged.

\section{References}

1. Cooper LF. Biologic determinants of bone formation for osseointegration: Clues for future clinical improvements. J Prosthet Dent 1998; 80: 439-449.

2. Lavenus S, Pilet P, Guicheux J, et al. Behaviour of mesenchymal stem cells, fibroblasts and osteoblasts on smooth surfaces. Acta Biomater 2011; 7: 1525-1534.

3. Oliveira SM, Alves NM and Mano JF. Cell interactions with superhydrophilic and superhydrophobic surfaces. J Adhes Sci Technol 2012; 28: 843-863.

4. Liu X, Chu PK and Ding C. Surface modification of titanium, titanium alloys, and related materials for biomedical applications. Mater Sci Eng $R$ 2004; 47: 49-121.

5. Niinomi M. Recent research and development in titanium alloys for biomedical applications and healthcare goods. Sci Technol Adv Mater 2003; 4: 445-454.

6. Drnovsek N, Daneu N, Recnik A, et al. Hydrothermal synthesis of a nanocrystalline anatase layer on Ti6A4V implants. Surf Coat Technol 2009; 203: 1462-1468.

7. Jimbo R, Sawase T, Baba K, et al. Enhanced initial cell responses to chemically modified anodized titanium. Clin Implant Dent Relat Res 2008; 10: 55-61.

8. Kaitainen S, Mahonen AJ, Lappalainen R, et al. TiO2 coating promotes human mesenchymal stem cell proliferation without the loss of their capacity for chondrogenic differentiation. Biofabrication 2013; 5: 025009.

9. Zhao L, Chang J and Zhai W. Effect of crystallographic phases of $\mathrm{TiO} 2$ on hepatocyte attachment, proliferation and morphology. J Biomater Appl 2005; 19: 237-252.

10. Fujishima A, Rao TN and Tryk DA. Titanium dioxide photocatalysis. J Photochem Photobiol C 2000; 1: 1-21.
11. Langlet M, Permpoon S, Riassetto D, et al. Photocatalytic activity and photo-induced superhydrophilicity of sol-gel derived $\mathrm{TiO} 2$ films. $J$ Photochem Photobiol A 2006; 181: 203-214.

12. Sawase T, Jimbo R, Baba K, et al. Photo-induced hydrophilicity enhances initial cell behavior and early bone apposition. Clin Oral Implants Res 2008; 19: 491-496.

13. Han Y, Chen D, Sun J, et al. UV-enhanced bioactivity and cell response of micro-arc oxidized titania coatings. Acta Biomater 2008; 4: 1518-1529.

14. Aita $\mathrm{H}$, Att $\mathrm{W}$, Ueno $\mathrm{T}$, et al. Ultraviolet light-mediated photofunctionalization of titanium to promote human mesenchymal stem cell migration, attachment, proliferation and differentiation. Acta Biomater 2009; 5: 3247-3257.

15. Aita H, Hori N, Takeuchi M, et al. The effect of ultraviolet functionalization of titanium on integration with bone. Biomaterials 2009; 30: 1015-1025.

16. Gao Y, Liu Y, Zhou L, et al. The effects of different wavelength UV photofunctionalization on micro-arc oxidized titanium. PLOS ONE 2013; 8: e68086.

17. Lorenzetti M, Pellicer E, Sort J, et al. Improvement to the corrosion resistance of Ti-based implants using hydrothermally synthesized nanostructured anatase coatings. Materials 2014; 7: 180-194.

18. Lorenzetti M, Biglino D, Novak S, et al. Photoinduced properties of nanocrystalline $\mathrm{TiO}_{2}$-anatase coating on Tibased bone implants. Mater Sci Eng C 2014; 37: 390-398.

19. Wenisch S, Trinkaus K, Hild A, et al. Human reaming debris: A source of multipotent stem cells. Bone 2005; 36 : 74-83.

20. Trinkaus K, Wenisch S, Siemers C, et al. Reaming debris: A source of vital cells! First results of human specimens. Unfallchirurg 2005; 108: 650-656.

21. Lorenzetti M, Bernardini G, Luxbacher T, et al. Surface properties of nanocrystalline $\mathrm{TiO}_{2}$ coatings in relation to the in vitro plasma protein adsorption. Biomed Mater 2014.

22. Pittenger MF, Mackay AM, Beck SC, et al. Multilineage potential of adult human mesenchymal stem cells. Science 1999; 284: 143-147.

23. Dumas V, Rattner A, Vico L, et al. Multiscale grooved titanium processed with femtosecond laser influences mesenchymal stem cell morphology, adhesion, and matrix organization. J Biomed Mater Res A 2012; 100A: 3108-3116.

24. Owen TA, Aronow M, Shalhoub V, et al. Progressive development of the rat osteoblast phenotype in vitro: reciprocal relationships in expression of genes associated with osteoblast proliferation and differentiation during formation of the bone extracellular matrix. $J$ Cell Physiol 1990; 143: 420-430.

25. Stein GS and Lian JB. Molecular mechanisms mediating proliferation/differentiation interrelationships during progressive development of the osteoblast phenotype. Endocr Rev 1993; 14: 424-442.

26. Weiss P. Cell contact. In: Bourne GH, Danielli JF (eds) International review of cytology. New York: Academic Press, 1958, pp.391-423. Available at: http://ac.els-cdn. com/S0074769608626819/1-s2.0-S0074769608626819- 
main.pdf?_tid $=5744 \mathrm{e} 042-9 \mathrm{~b} 0 \mathrm{~b}-11 \mathrm{e} 4-\mathrm{addb}-00000 \mathrm{aab0f6b}$ \&acdnat $=$

1421143553_3dd2393b4a2c91e7061a04d64a6168b5.

27. Dalby MJ. Cellular response to low adhesion nanotopographies. Int J Nanomed 2007; 2: 373-381.

28. Salido M, Vilches JI, Gutierrez JL, et al. Actin cytoskeletal organization in human osteoblasts grown on different dental titanium implant surfaces. Histol Histopathol 2007; 22: 1355-1364.

29. Rosales-Leal JI, Rodríguez-Valverde MA, Mazzaglia G, et al. Effect of roughness, wettability and morphology of engineered titanium surfaces on osteoblast-like cell adhesion. Colloids Surf A: Physicochem Eng Aspects 2010; 365: 222-229.

30. Yoneyama Y, Matsuno T, Hashimoto Y, et al. In vitro evaluation of $\mathrm{H} 2 \mathrm{O} 2$ hydrothermal treatment of aged titanium surface to enhance biofunctional activity. Dent Mater J 2013; 32: 115-121.

31. Olivares-Navarrete R, Hyzy SL, Hutton DL, et al. Direct and indirect effects of microstructured titanium substrates on the induction of mesenchymal stem cell differentiation towards the osteoblast lineage. Biomaterials 2010; 31: 2728-2735.

32. Bang S-M, Moon H-J, Kwon Y-D, et al. Osteoblastic and osteoclastic differentiation on SLA and hydrophilic modified SLA titanium surfaces. Clin Oral Implants Res 2014; 25(7): 831-837.

33. Zhao G, Schwartz Z, Wieland M, et al. High surface energy enhances cell response to titanium substrate microstructure. J Biomed Mater Res A 2005; 74: 49-58.

34. Eriksson C, Nygren $\mathrm{H}$ and Ohlson K. Implantation of hydrophilic and hydrophobic titanium discs in rat tibia: Cellular reactions on the surfaces during the first 3 weeks in bone. Biomaterials 2004; 25: 4759-4766.

35. Golub EE and Boesze-Battaglia K. The role of alkaline phosphatase in mineralization. Curr Opin Orthop 2007; 18: 444-448.

36. Lai M, Cai K, Hu Y, et al. Regulation of the behaviors of mesenchymal stem cells by surface nanostructured titanium. Colloids Surf B: Biointerfaces 2012; 97: 211-220.
37. Lian JB and Stein GS. Development of the osteoblast phenotype: Molecular mechanisms mediating osteoblast growth and differentiation. Iowa Orthop J 1995; 15: 118-140.

38. Bico J, Thiele U and Quere D. Wetting of textured surfaces. Colloids Surf A: Physicochem Eng Aspects 2002; 206: 41-46.

39. Att W, Hori N, Takeuchi M, et al. Time-dependent degradation of titanium osteoconductivity: An implication of biological aging of implant materials. Biomaterials 2009; 30: 5352-5363.

40. Guney A, Kara F, Ozgen O, et al. Surface modification of polymeric biomaterials. In: Taubert A, Mano JF, Rodriguez-Cabello JC (eds) Biomaterials surface science. New York: Wiley-VCH Verlag GmbH \& Co. KGaA, 2013, pp.89-158.

41. Baier RE, Meyer AE, Natiella JR, et al. Surface properties determine bioadhesive outcomes: Methods and results. J Biomed Mater Res 1984; 18: 337-355.

42. Iwasa F, Tsukimura N, Sugita Y, et al. TiO2 micro-nanohybrid surface to alleviate biological aging of UV-photofunctionalized titanium. Int $J$ Nanomed 2011; 6: $1327-1341$.

43. Iwasa F, Hori N, Ueno T, et al. Enhancement of osteoblast adhesion to UV-photofunctionalized titanium via an electrostatic mechanism. Biomaterials 2010; 31: 2717-2727.

44. Hori N, Ueno T, Minamikawa H, et al. Electrostatic control of protein adsorption on UV-photofunctionalized titanium. Acta Biomater 2010; 6: 4175-4180.

45. Hori N, Iwasa F, Tsukimura N, et al. Effects of UV photofunctionalization on the nanotopography enhanced initial bioactivity of titanium. Acta Biomater 2011; 7: 3679-3691.

46. Tengvall $P$ and Lundström I. Physico-chemical considerations of titanium as a biomaterial. Clin Mater 1992; 9: 115-134.

47. Ellingsen JE. A study on the mechanism of protein adsorption to TiO2. Biomaterials 1991; 12: 593-596. 